Although the prothrombin activity was lowered, the other coagulation results were not appreciably different one week after the start of the regime of gradual withdrawal. The increase of Factor VIII concentration was still significant but less marked at the end of the second week.

By the third week of the withdrawal regime the prolongation of the prothrombin time was no longer significant, although the Factor VII level was still reduced (see Chart). By this time the increase of Factor VIII concentration had also disappeared. Unlike the previous " rebound" study, where the cephalin time was dramatically shortened a week after treatment was completely stopped, in this investigation the results at the same stage were not significantly different from the parallel normals. Only when the cephalin-time results were compared with the larger group of 80 normals did the shortening achieve the level of significance.

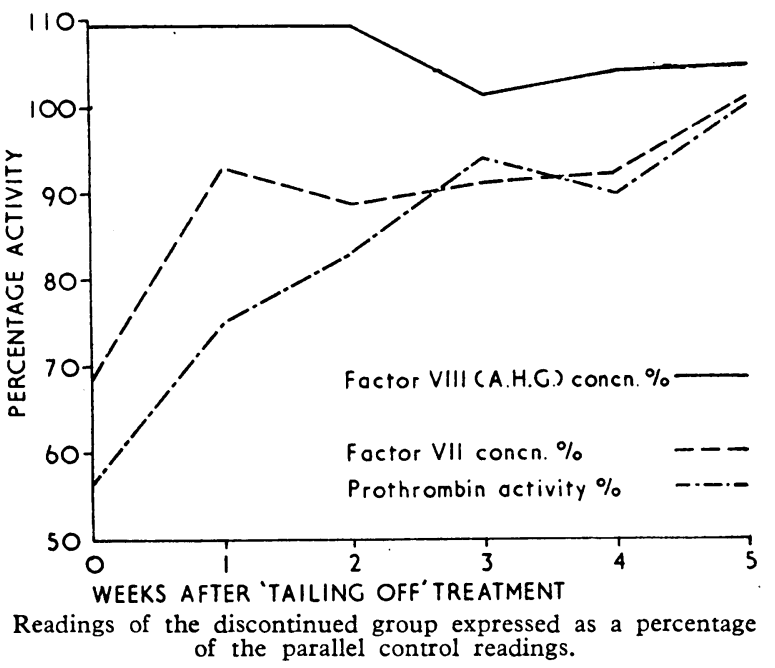

There was no evidence of rebound hypercoagulability in the extrinsic blood-coagulation system.

\section{Discussion}

The present regime of gradual withdrawal of anticoagulants appears to have eliminated the rebound hypercoagulability in the extrinsic (tissue) coagulation system and prevented dramatic changes in the intrinsic system found in the previous study. The striking feature of the previous study had been the reduction in cephalin times at the end of the first week after abrupt withdrawal of treatment. This was associated with an unsuspected increase in the concentration of Factor VIII which we found was present at the end of a period of long-term anticoagulant therapy. This increase of Factor VIII persisted for at least two weeks after stopping full-dosage anticoagulant treatment.

In this investigation, towards the end of their period of the "tailing off" regime, the discontinued group showed less dramatic shortening of their cephalin times, which persisted until one week after the treatment was completely stopped. The clinical importance of the later less-marked " rebound" hypercoagulability found in the cephalin-time tests with the regime of gradual withdrawal is uncertain. The results do suggest that, although the main danger of " rebound" hypercoagulability has been considerably reduced, the regime should be further modified to provide an even more gradual scheme of withdrawal of oral anticoagulant treatment.

\section{Summary}

A study has been made of the effect of a regime of gradual withdrawal of oral anticoagulant on "rebound" hypercoagulability. The regime entailed the "tailing off" of anticoagulant dosage over a four-week period in patients who had been on long-term anticoagulants for an average of 14 months.

The results of coagulation studies suggest that, although the main danger of "rebound" hypercoagulability has been considerably reduced, the regime should be further modified to provide an even more gradual withdrawal of anticoagulant treatment.

A grant for thrombosis research from Manchester Regional Hospital Board is gratefully acknowledged. We are grateful to Dr. M. C. G. Israels for the donation of haemophilic plasma used in the assays.

\section{REFERENCE}

Poller, L., and Thomson, J. (1964). Lancet, 2, 62.

\title{
Frequency of Haemoglobin S and Glucose-6-Phosphate Dehydrogenase Deficiency in Southern Tanzania
}

\author{
H. R. MARTI,* M.D. ; K. SCHOEPF, $†$ M.D. ; O. R. GSELL,* M.D.
}

Brit. med. f., 1965, 1, 1476-1477

A series of 1,232 blood samples were examined in the Ulanga district of Tanzania during July and August 1964 . The survey was carried out in Ifakara, a town in the Kilombero Valley at $780 \mathrm{ft}$. ( $238 \mathrm{~m}$.) above sea-level, with a high incidence of malaria throughout the year. We compared 404 inhabitants of Ifakara with 173 persons living in the highland of Mahenge and other areas of approximately 3,300 ft. $(1,005 \mathrm{~m}$.) altitude with a lower incidence of malaria (transmission rate during less than six months of the year (Atlas, 1948)).

\footnotetext{
- Out-patient Department of Internal Medicine, University of Basle, Switzerland.

t St. Francis Hospital, Ifakara, Tanzania.
}

Of the 1,232 blood samples, 878 were taken from outpatients, 149 from in-patients of the St. Francis Hospital, Ifakara, and 205 from pupils and students of the Upper Primary School, the Girls' Middle School, and the Rural Aid Centre, Ifakara. Of the subjects examined, 1,198 belonged to local Bantu tribes, 8 were Masai, and 26 were citizens of other parts of Tanzania or of the surrounding countries. All 1,232 persons examined (458 males and 774 females) were either adults or children estimated to be 12 years of age and older. The origin of the 1,232 persons was as follows: 404 were inhabitants of Ifakara, 629 were living in other towns or 
villages of the Kilombero Valley, 173 came from the surrounding mountain areas, and 26 came from different regions outside of the Ulanga district.

Of the 1,232 blood samples, 1,109 were investigated for abnormal haemoglobins and glucose-6-phosphate dehydrogenase deficiency and 123 for abnormal haemoglobins alone. Citrated blood was examined for enzyme activity within four hours and for haemoglobin $S$ within 10 hours after venous puncture. The erythrocytes were washed once with saline and haemolysed with distilled water. The haemoglobin was examined in 125 cases by paper electrophoresis, and in 1,107 cases with the aid of agar gel technique; in both methods veronal buffer $p \mathrm{H} 8.6$ was used. After agar gel electrophoresis the haemoglobin fractions were stained by means of the benzidine reaction. Haemoglobin $S$ was identified by the sickling phenomenon of the red cells. For the sickling test a $2 \%$ solution of $\mathrm{Na}_{2} \mathrm{~S}_{2} \mathrm{O}_{4}$ was used. The glucose-6-phosphate dehydrogenase activity was assayed with the Brewer test read by eye (Brewer et al., 1960).

\section{Results}

The frequency of haemoglobin $S(\mathrm{Hb} S$ ) and glucose-6phosphate dehydrogenase (G-6-PD) deficiency is summarized in Table I. 222 heterozygous and 2 homozygous carriers of $\mathrm{Hb} S$ were found. The previously unknown homozygous cases were an approximately 12-year-old boy and a 16-yearold girl with hepatosplenomegaly and marked anaemia. Of the 222 heterozygous persons, one was a Masai man and 221 belonged to the local Bantu tribes. No difference between healthy persons and patients could be found. A large amount of methaemoglobin with a pure brown colour of the tube was found in the Brewer test in 59 males and 18 females, indicating a very low G-6-PD activity. An intermediate result was obtained in 52 females. Out of 408 males, 65 showed the presence of $\mathrm{Hb} S$ trait only, 49 revealed G-6-PD deficiency and 10 had a combination of both. The combination therefore occurred in $13 \%$ of the $\mathrm{Hb} \mathrm{S}$ carriers and in $17 \%$ of the G-6-PD deficient males.

Comparison of the results found in inhabitants of Ifakara with high malaria incidence with those of persons living in

\begin{tabular}{l} 
TABLE I.-Frequency of Haemoglobin $\begin{array}{c}S \text { and } \\
\text { Dehydrogenase }\end{array}$ Deficiency \\
\hline \\
\end{tabular}

TABLE II.-Different Frequency of Haemoglobin $S$ and Glucose-6phosphate Dehydrogenase Deficiency in Ifakara and Mountain Areas

\begin{tabular}{|c|c|c|c|c|c|}
\hline & & & \multirow{2}{*}{$\begin{array}{c}\text { No. of } \\
\text { Persons } \\
\text { Examined }\end{array}$} & \multicolumn{2}{|c|}{$\begin{array}{l}\text { Persons with } \\
\text { Abnormality }\end{array}$} \\
\hline & & & & No. & $\%$ \\
\hline $\begin{array}{l}\text { Ifakara: } \\
\text { Hb } S \text { in males and females } \\
\text { G-6-PD deficiency in males } \\
\text { Mountain areas }\end{array}$ & $\therefore$ & $\because$ & $\begin{array}{l}404 \\
109\end{array}$ & $\begin{array}{l}89 \\
20\end{array}$ & $\begin{array}{l}22 \\
18\end{array}$ \\
\hline $\begin{array}{l}\text { Hb } S \text { in males and females } \\
\text { G-6-PD deficiency in males }\end{array}$ & $\because$ & $\because$ & $\begin{array}{r}173 \\
59\end{array}$ & $\begin{array}{r}18 \\
5\end{array}$ & $\begin{array}{r}10 \\
8\end{array}$ \\
\hline
\end{tabular}

mountain areas with lower malaria incidence is shown in Table II. In the whole series of 1,232 persons no other abnormal haemoglobin than $\mathrm{Hb} \mathrm{S}$ was detected.

\section{Comments}

With $18 \%$ the $\mathrm{Hb} \mathrm{S}$ frequency is of the same high order as found in Uganda (Marsden and Blackman, 1964) and Northern Rhodesia (English, 1945). Other abnormal haemoglobins, and especially $\mathrm{Hb} \mathrm{C}$, are absent; this confirms the previous observation of Lehmann and Mackey (1955), who examined 104 blood samples from adult East Africans living in Dar-es-Salaam. Despite the high frequency of $14.5 \%$ G-6PD deficiency in males, none of the 59 males deficient of enzyme ever had a known haemolytic crisis; six of them had been treated with streptomycin and para-aminosalicylic acid for pulmonary tuberculosis. The results in 701 women examined indicate that only about one-third of the expected heterozygous females are detected with the aid of the Brewer test.

Lewis (1964) discussed a correlation between G-6-PD deficiency and $\mathrm{Hb} \mathrm{S}$, admitting that the enzyme deficiency could exert a beneficial effect on sickle-cell disease. The results of the present investigation, however, indicate that the combination of the two abnormalities is not more frequent than is expected by independent random transmission of both.

The comparison of the Bantu population living in Ifakara with a high incidence of malaria with the population in the neighbouring mountain areas with lower malaria frequency shows a statistically significant difference of $\mathrm{Hb} \mathrm{S}$ incidence in the two regions $(p=0.0015)$. A similar difference is also seen in the frequency of G-6-PD deficiency, but to produce significant results our number of examined males from the mountain areas was too small $(p=0.14)$.

\section{Summary}

In a series of 1,232 native Africans in the Ulanga district of Tanzania an incidence of $18.2 \% \mathrm{Hb} \mathrm{S}$ and a frequency of $14.5 \%$ glucose-6-phosphate dehydrogenase deficiency in males were found. No connexion between the two abnormalities was detectable. Comparison of an area with a high malaria incidence with an area with a lower incidence revealed a significant difference in $\mathrm{Hb} \mathrm{S}$ inheritance and a probable difference in the frequency of glucose-6-phosphate dehydrogenase deficiency.

We are grateful to Professor R. Geigy, Director of the Swiss Tropical Institute, Basle, Switzerland, for his aid and kind hospitality in his laboratories of the Rural Aid Centre, Ifakara. The investigation was supported by grant No. 3087 of the Swiss National Foundation for the Development of Scientific Research.

\section{REFERENCES}

Atlas of the Tanganyika Territory, 1948, 2nd ed., Survey Division, Department of Lands and Mines, Dar-es-Salaam.

Brewer, G. J., Tarlov, A. R., and Alving, A. S. (1960). Bull. Wld Hlth Org., 22, 633.

English, R. B. (1945). S. Afr. med. 7., 19, 431

Lehmann, H., and Mackey, J. P. (1955). Man, p. 186.

Lewis, R. A. (1964). Abstract 9th Congress of International Society of Haematology, L: 9, Stockholm.

Marsden, P. D., and Blackman, V. (1964). E. Afr. med. F., 41, 305. 